\title{
PENGARUH DIMENSI KUALITAS LAYANAN TERHADAP KEPUASAN PASIEN RAWAT INAP DI RUMAH SAKIT UMUM DAERAH MOROWALI
}

\author{
SULVIANDANI \\ SYAMSUL BACHRI \\ RAHMAT MUBARAQ \\ Program Studi S1 Manajemen Fakultas Ekonomi Universitas Tadulako \\ Email: sulviandani.saleng@gemail.com
}

\begin{abstract}
The objective of this research is to find out the effect of service quality physical evidence, reliability, responsiveness, assurance and empathy on patients statisfaction in morowali regional hospital. The research problem is whether the quality of service consists of physical evidence, reliability, assurance, responsiveness and empathy simultaneously and partially significan effect on patients satisfaction in morowali regional general hospital. To prove the hypothesis, the researcher used multiple linear regression analysis tool. The sample draw by accidental sampling technique, where anyone who meet at the location of the research direcly determined as a sample if they are suitable as a source of data, data were collected distribution of questionnaires. To prove the hypothesis simultaneously uses the F test while to prove each hypothesis variable uses t teste.
\end{abstract}

Keywords: service quality, patients satisfaction

Penelitian ini bertujuan untuk mengetahui pegaruh kualitas pelayanan, bukti fisik, kehandalan, daya tanggap, jaminan dan empati terhadap kepuasan pasien pada rumah sakit umum daerah morowali. Permasalah dalam penelitian ini apakah kualitas layanan yang terdiri dari bukti fisik, kehandalan, jaminan, daya tanggap, dan empati secara simultan dan parsial berpengaruh signifikan terhadap kepuasan pasien dirumah sakit umum daerah morowali.Untuk membuktikan hiopotesis tersebut peneliti menggunakan alat analisis regresi linear berganda. Penarikan sampel menggunakan metode accidental sampling yaitu siapapun yang kebetulan ditemui dilokasi penelitian langsung ditetapkan sebagai sampel jika kebetulan yang ditemui cocok sebagai sumber data, pengumpulan data penulis menggunakan metode pembagian kuesioner. Untuk membuktikan hipotesis secara serempak penulis menggunakan alat uji $\mathrm{F}$ sedangkan untuk membuktikan masing masing hipotesis variable penulis menggunakan alat uji t.

Kata Kunci: kualitas layanan, kepuasan pasien

\section{PENDAHULUAN}

Layanan yang baik merupakan salah satu kunci keberhasilan dalam berbagi usaha yang bersifat jasa. Pelayanan kesehatan merupakan konsep yang digunakan untuk menyediakan layanan kesehatan pada masyarakat. Menurut pendapat Prof. Dr Soekidjo Notoatmojo, ini merupakan sub sistem dari layanan kesehatan dimana tujuan utamanya adalah pelayanan pencegahan atau preventif dan peningkatan kesehatan (promotif) dengan sasaran masyarakat. Selain itu, ada pula yang memberikan pengertian bahwa pelayanan kesehatan merupakan upaya yang dilakukan baik sendiri atau bersamasama di dalam sebuah organisasi untuk memelihara kesehatan, meningkatkan kesehatan, mencegah, dan menyembuhkan penyakit serta memulihkan kesehatan masyarakat.

Tenaga yang melayani pelayanan kesehatan masyarakat adalah ahli kesehatan masyarakat. Fokus utamanya adalah untuk mencegah penyakit dan sasaran utamanya tentu adalah masyarakat secara menyeluruh. Para tenaga ahli biasanya mencari cara yang paling efektif dan efisien dalam melayani pasiennya. Mereka boleh menarik perhatian masyarakat dan menjalankan fungsi dengan mengorganisirnya. Walaupun demikian, para tenaga pelaksana juga tetap mendapat dukungan undang-undang. Perbaikan kualitas jasa pelayanan kesehatan dapat dimulai dengan mengevaluasi 


\section{Sulviandani}

setiap unsur-unsur yang berperan dalam membentuk kepuasan pasien. pelayanan kesehatan yang dapat memuaskan setiap pemakai jasa pelayanan sesuai dengan tingkat kepuasan rata-rata penduduk serta penyelenggaraannya sesuai dengan kode etik dan standar pelayanan yang telah ditetapkan. Dua unsur penting dalam upaya peningkatan pelayanan kesehatan adalah tingkat kepuasan pasien dirawat inap sebagai pengguna jasa dan pemenuhan standar pelayanan yang telah ditetapkan.

RSUD Morowali adalah sebagai salah satu sarana kesehatan untuk memberikan pelayanan kesehatan kepada masyarakat dan memiliki peran yang sangat penting dalam mempercepat peningkatan derajat kesehatan masyarakat. Hal ini menuntut penyedia jasa pelayanan kesehatan yakni RSUD Morowali untuk meningkatkan kualitas pelayanan yang lebih baik, tidak hanya pelayanan yang bersifat penyembuhan penyakit tetapi juga mencakup pelayanan yang bersifat pencegahan. Oleh karena itu, Rumah sakit umum daerah Morowali (RSUD Morowali) dituntut untuk memberikan pelayanan rawat inap yang bermutu sesuai dengan standar yang ditetapkan dan dapat menjangkau seluruh lapisan masyarakat yang ada di Morowali.

\section{KAJIAN LITERATUR DAN PENGEMBANGAN HIPOTESIS}

\section{Manajemen Pemasaran}

Menurut Kotler (2004:7) pemasaran adalah suatu peroses social dan manajerial yang di dalam individu dan kelompok mendapatkan apa yang mereka butuhkan dan inginkan dengan menciptakan, menawarkan, dan menukarkan produk yang bernilai dengan pihak lain. Peranan pemasaran saat ini tidak hanya menyampaikan produk atau jasa hingga tangan konsumen tetapi juga bagaimana produk atau jasa tersebut dapat memberikan kepuasan kepada pelanggan dengan menghasilkan laba. Sasaran dari pemasaran adalah menarik pelanggan baru dengan menjanjikan nilai superior, menetapkan harga menarik, mendistribusikan produk dengan mudah, mempromosikan secara efektif serta mempertahankan pelanggan yang sudah ada dengan tetap memegang prinsip kepuasan pelanggan.

\section{Kualitas Layanan}

Kualitas adalah sebuah kata yang bagi penyedia jasa merupakan sesuatu yang harus dikerjakan dengan baik. Kualitas sebagai suatu strategi dasar bisnis yang menghasilkan barang dan jasa yang memenuhi kebutuhan dan kepuasan konsumen internal dan eksternal, eksplisit dan implisit atau dapat pula didefenisikan sebagai seluruh ciri serta sifat suatu produk atau pelayanan yang berpengaruh pada kemampuan untuk memuaskan kebutuhan yang dinyatakan atau tersirat. Sedangkan pelayanan mengendung pengertian yaitu setiap kegiatan atau manfaat yang diberikan oleh suatu pihak kepada pihak lain yang dasarnya tidak berwujud yang tidak pula berakibat kepemilikan sesuatu (Kotler dan Keller 2009:83).

\section{Dimensi Kualitas Layanan}

Kualitas layanan dapat dijelaskan sebagai persepsi pelanggan terhadap perbedaan antara pelayanan yang diharapkan dengan kinerja yang dapat mempengaruhi tngkat kepuasan. Selain itu juga kualitas pelayanan adalah ukuran seberapa bagus pelayanan yang diberikan kepada pengunjung melalui pemenuhan kebutuhan pengunjung sehingga dapat memperoleh pelayanan yang diberikan. Menurut Kotler dan Keller (2009:52) mengidentifikasikan bahwa terdapat lima dimensi yang digunakan konsumen dalam mengevaluasi kualitas layanan yang dikenal dengan istilah SERVQUAL, antara lain adalah:

1. Bukti fisik (tangibles) adalah kemampuan suatu perusahaan dalam menunjukan eksistensinya kepada pihak eksternal.

2. Kehandalan (reliability) yaitu kemampuan suatu perusahaan untuk memberikan layanan sesuai yang dijanjikan secara akurat dan terpercaya.

3. Jaminan (assurance) adalah pengetahuan, kesopansantunan, dan kemampuan para pegawai perusahaan untuk menumbuhkan rasa percaya para konsumen kepada perusahaan 
4. Daya tanggap (responsiveness) suatu kebijakan untuk membantu dan memberikan layanan yang cepat dan tepat kepada konsumen, dengan menyampaikan informasi yang jelas.

5. Empati (emphaty) dengan memberikan perhatian yang tulus dan bersifat individual atau pribadi yang diberikan kepada para konsumen dengan berupaya memahami keinginan konsumen.

\section{Kepuasan Pelanggan}

Lupiyoadi (2013:228) mengungkapkan kepuasan merupakan tingkat perasaan dimana seseorang menyatakan hasil perbandingan hasil kinerja produk/jasa yang diterima atau diharapkan, dalam memberikan pelayanan kepada pelanggan pihak penyedia dan pemberi layanan harus selalu berupaya untuk mengacu kepada tujuan utama pelayanan, yaitu pencapaian kepuasan konsumen atau kepuasan pelanggan.

\section{Hipotesis}

1. Variabel kualitas layanan secara serempak berpengaruh signifikan terhadap kepuasan pasien rawat inap di Rumah Sakit Umum Daerah morowali

2. Dimensi Bukti fisik berpengaruh signifikan terhadap kepuasan pasien rawat inap di Rumah Sakit Umum Daerah Morowali.

3. Dimensi Kehandalan berpengaruh signifikan terhadap kepuasan pasien rawat inap di Rumah Sakit Umum Daerah Morowali.

4. Dimensi Jaminan berpengaruh signifikan terhadap kepuasan pasien rawat inap di Rumah Sakit Umum Daerah Morowali.

5. Dimensi Daya tanggap berpengaruh signifikan terhadap kepuasan pasien rawat inap di Rumah Sakit Umum Daerah Morowali.

6. Dimensi Empati berpengaruh signifikan terhadap kepuasan pasien rawat inap di Rumah Sakit Umum Daerah Morowali.

\section{METODE PENELITIAN}

Jenis penelitian ini adalah deskriptif dan kausal. Menurut Arikunto (2008:8) menjelaskan bahwa penelitian deskriptif adalah penelitian yang bertujuan untuk memperoleh deskriptif tentang ciri-ciri nariabel. Sedangkan riset kausal menurut Umar (2008:105) berguna untuk menganalisis hubunganhubungan antara variabel dengan variabel lainnya. Adapun lokasi penelitian ini yang dilaksanankan pada Rumah Sakit Umum Daerah Morowali. Penelitian ini akan dilaksanakan pada bulan Desember 2017 sampai selesai. Penelitian ini dilaksanakan pada pasien rawat inap. Alasan melakukan penelitian disini karna untuk menuntut penyedia jasa pelayanan kesehatan yakni RSUD Morowali untuk meningkatkan kualitas pelayanan yang lebih baik, tidak hanya pelayanan yang bersifat penyembuhan penyakit tetapi juga mencakup pelayanan.

Metode Pengumpulan Data yang digunakan terdiri dari:

1. Wawancara (Interview)

Merupakan bentuk pengumpulan data yang paling sering digunakan. Wawancara dilakukan dengan mengajukan pertanyaan secara langsung kepada pengelola dan masyarakat yang pernah berobat dirumah sakit umum daerah morowali. Metode ini di lakukan dengan cara tanya jawab baik kepada pimpinan RSUD Morowali, karyawan, masyarakat yang di perkenankan untuk memberikan keterangan sehubungan dengan penelitian yang di lakukan.

2. Kuesioner (Angket)

Kuesioner adalah suatu teknik pengumpulan informasi yang memungkinkan analis mempelajari sikap-sikap, keyakinan perilaku dan karakteristik beberapa orang utama didalam organisasi yang bisa terpengaru oleh sistem yang diajukan oleh sistem yang sudah ada. Pengumpulan data 
Sulviandani

dilakukan dengan memberikan daftar pertanyaan untuk diisi oleh responden yaitu pasien rawat inap Rumah Sakit Umum Daerah Morowali.

3. Observasi

Observasi adalah Proses pengamatan dan pencatatan secara sistematis mengenai gejala-gejala yang diteliti. Observasi ini menjadi salah satu dari teknik pengumpulan data apabila sesuai dengan tujuan penelitian, yang direncanakan dan dicatat secara sistematis, serta dapat dikontrol keandalan (reliabilitas) dan kesahihannya (validitasnya), Pengamatan secara langsung terhadap pasien dan pengelola Rumah Sakit Umum Daerah Morowali untuk memperoleh data yang harus dikumpulkan dalam penelitian.

4. Dokumentasi

Dokumentasi adalah sebuah cara yang dilakukan untuk menyediakan dokumen-dokumen dengan dengan menggunakn bukti yang akurat dari pencatatan sumber-sumber informasi khusus dari rumah sakit seperti arsip dari Rumah Sakit. Dokumentasi ini digunakan untuk mendapatkan keterangan, dokumentasi juga biasanya juga digunakan dalam sebuah laporan pertanggung jawaban.

Analisis data penelitian menggunakan regresi linier berganda. Analisis regresi berganda digunakan untuk mengukur kekuatan hubungan antara dua variabel atau lebih. Juga menunjukan arah hubungan variabel dependen dengan variabel independen (Ghozali, 2009:86). Model regresi linear berganda terdapat variabel independen $\mathrm{X} 1, \mathrm{X} 2$ dengan variabel dependen $\mathrm{Y}$, maka secara hubungan linear diformulasikan sebagai berikut (Ghozali, 2009:89):

$$
\mathrm{Y}=\mathrm{b} 0+\mathrm{b} 1 \mathrm{X} 1+\mathrm{b} 2 \mathrm{X} 2 . . . \mathrm{bnXn}+\mathrm{e}
$$

\section{HASIL DAN PEMBAHASAN}

\section{Uji Regresi Linear Berganda}

\section{Tabel 1}

Hasil Perhitungan Regresi Linear Berganda

\begin{tabular}{|c|c|c|c|c|c|}
\hline \multirow{2}{*}{ Variabel Independen } & \multicolumn{2}{|c|}{$\begin{array}{l}\text { Unstandardized } \\
\text { Coefficients }\end{array}$} & \multirow{2}{*}{$\begin{array}{c}\begin{array}{c}\text { Standardized } \\
\text { Coefficients }\end{array} \\
\text { Beta }\end{array}$} & \multirow{2}{*}{$\mathrm{T}$} & \multirow{2}{*}{ Sig. } \\
\hline & B & $\begin{array}{l}\text { Standar } \\
\text { Eror }\end{array}$ & & & \\
\hline $\mathrm{C}=$ Costanta & .140 & .673 & & .208 & .836 \\
\hline Bukti Fisik (X1) & .221 & .096 & .253 & 2.304 & .025 \\
\hline Kehandalan (X2) & .287 & .089 & .369 & 3.233 & .002 \\
\hline Jaminan (X3) & .188 & .081 & .255 & 2.312 & .025 \\
\hline Daya Tanggap (X4) & .233 & .071 & .337 & 3.295 & .002 \\
\hline Empati (X5) & .040 & .066 & .067 & .614 & .542 \\
\hline \multicolumn{6}{|l|}{$\begin{array}{l}\text { Multiple R }=0,687^{\mathrm{a}} \\
\text { R Square }\left(\mathrm{R}^{2}\right)=0,472 \\
\text { Sig. F }=.000^{\mathrm{b}}\end{array}$} \\
\hline
\end{tabular}

Berdasarkan tabel tersebut, dapat ditulis dalam bentuk persamaan regresi linear berganda. Lebih jelasnya bentuk persamaan tersebut dapat dilihat sebagai berikut:

$$
Y=0,140+0,221 X 1+0,287 X 2+0,188 X 3+0,233 X 4+0,040 \times 5+e
$$


Persamaan di atas menunjukan, variable independen yang dianalisis berupa variable (X1, X2, X3, $\mathrm{X} 4, \mathrm{X} 5)$ memberi pengaruh terhadap variable dependen (Y) model analisis regresi kepuasan pasien di RSUD Morowali dari persamaan diatas dapat dijelaskan.

1. Untuk nilai konstanta sebesar 0,140 berarti kepuasan pasien di RSUD Morowali sebelum adanya variabel independen (X1, X2, X3, X4, dan X5) adalah sebesar 0,140.

2. Koefisien regresi variabel bukti fisik, nilai koefisien variabel bukti fisik sebesar 0,221 ini berarti terjadi pengaruh yang positif antara bukti fisik dengan kepuasan pasien rawat inap. Atau dengan kata lain apa bila variabel bukti fisik bertambah kearah positif maka kepuasan pasien rawat inap di RSUD Morowali akan meningkat.

3. Koefisien regresi variabel kehandalan, nilai koefisien variabel kehandalan sebesar 0,287 memiliki arti bahwa terdapat hubungan positif antara variabel kehandalan dengan kepuasan pasien rawat inap akan meningkat.

4. Koefisien regresi variabel jaminan, nilai koevisien variabel jaminan sebesar 0,118 memiliki arti bahwa terdapat hubungan positif antara variabel jaminan dengan kepuasan pasien rawat inap atau dengan kata lain apa bila variabel jaminan bertambah kearah positif.

5. Koefisien regresi variabel daya tanggap, nilai koefisien variabel daya tanggap sebesar 0,233 memiliki arti bahwa terdapat hubungan positif antara variabel daya tanggap dengan kepuasan pasien rawat inap atau dengan kata lain apabila variable daya tnaggap bertambah kearah positif.

6. Koefisien regresi variabel empati, nilai koefisien empati sebesar 0,040 memiliki arti bahwa terdapat hubungan positif antara variabel empati dengan kepuasan pasien rawat inap atau dengan kata lain apa bila variabel empati bertambah kearah positif, maka kepuasan pasien rawat inap akan meningkat.

\section{KESIMPULAN DAN SARAN}

\section{Kesimpulan}

1. Kualitas pelayanan yang terdiri atas bukti fisik, kehandalan, jaminan, daya tanggap, empati, secara serempak berpengaruh signifikan terhadap kepuasan pasien di RSUD Morowali.

2. Bukti Fisik (X1) berpengaruh signifikan terhadap kepuasan pasien rawat inap di RSUD Morowali

3. Kehandalan (X2) berpengaruh signifikan terhadap kepuasan pasien rawat inap di RSUD Morowali

4. Jaminan (X3) berpengaruh signifikan terhadap kepuasan pasien rawat inap di RSUD Morowali

5. Daya Tanggap (X4) berpengaruh signifikan terhadap kepuasan pasien rawat inap di RSUD Morowali

6. Empati (X5) berpengaruh tidak signifikan terhadap kepuasan pasien rawat inap di RSUD Morowali.

\section{Saran}

1. Rumah Sakit Umum Daerah Morowali harus meningkatkan kebersihan, terutama kebersihan toilet sehingga pasien merasa nyaman berada di dalam rumah sakit tersebut, adapun yang perlu dipertahankan oleh pihak rumah sakit ini adalah kamar dan tempat tidur agar pasien rawat inap merasa puas dengan pelayanan yang diberikan.

2. Rumah Sakit Umum Daerah Morowali harus meningkatkan ketepatan waktu para medis dalam pemeriksaan sehingga pasien rawat inap mendapatkan perawatan yang mereka inginkan, adapun yang perlu dipertahankan yaitu kemampuan dokter yang dalam melakukan pemeriksaan agar pasien merasa nyaman dan puas terhadap pelayanan yang diberikan.

3. Jaminan keamanan pelayanan para medis Rumah Sakit Umum Daerah Morowali sangat baik namun harus ditingkatkan agar para pengunjung dan pasien merasa aman dan nyaman terhadap pelayanan yang diberikan., 
4. Kesiapan para medis untuk merespon permintaan pasien harus lebih ditingkatkan agar pasien rawat inap Rumah Sakit Umum Daerah Morowali puas dengan pelayanannya dan mau kembali berobat di Rumah Sakit Umum Daerah Morowali. Kecepatan para medis dalam melayani pasien rawat inap sangat baik akan tetapi kesiapan mereka harus lebih, yang dimaksud adalah kemudahan melakukan hubungan baik dengan pasien, perhatian pribadi, dan memahami kebutuhan pasien.

5. Rumah Sakit Umum Daerah Morowali harus meningkatkan variabel dokter memberikan perhatian khusus kepada pasien agar pasien rawat inap merasa puas dengan pengobatan yang diberikan dokter. Dan yang perlu ditingkatkan yaitu para medis memberikan perhatian khusus menurut penilaian pasien belum sesuai dengan yang diharapkan oleh pasien rawat inap di Rumah Sakit Umum Daerah Morowali.

6. Disarankan kepada peneliti selanjutnya yang ingin meneliti objek yang sama, disarankan untuk memasukan variable lain yang tidak diteliti pada penelitian ini, dan juga perlu menggunakan sampel yang lebih besar guna mengakuratkan hasil penelitian.

\section{REFERENSI}

Aji, Kartika Wahyu. (2011). Analisis Pengaruh Kualitas Pelayanan, Tarif dan Fasilitas Terhadap Kepuasan Pasien (Studi Pada Pasien Klinik As Syifa di Kab. Bekasi).

Arikunto, Suharsimi. (2008). Prosedur Penelitian: Suatu Pendekatan Praktek. (Edisi Keempat) Jakarta: Rineka Cipta

Arlina Nurbaity Lubis dan Martin. (2009). Pengaruh Harga dan Kualitas Pelayanan terhadap Kepuasan Pasien Rawat Inap di RSU Deli Medan, Universitas Sumatera Utara, Januari 2009: 21-24.

Atmawati, R dan Wahyudin, A. (2007). Analisis Pengaruh Kualitas Pelayanan Terhadap Kepuasan Konsumen Pada Matahari Departement Store Di Solo Grand Mall. Surakarta: Jurnal Daya Saing, Program MM-UMS.

Dewi, (2017), Pengaruh Kualitas Layanan Terhadap Kepuasan Nasabah Pada PT. Mandala Multi Finance Cabang Palu, Jurnal Ilmu Manajemen Universitas Tadulako, Vol. 3 No. 2, 2017.

Ghozali, Imam. (2009). Aplikasi Analisis Multivariate Dengan Program SPSSS, Cetakan Ke IV, Badan Penerbit Universitas Diponegoro, Semarang.

Kotler. Pilip. (2004). Manajemen Pemasaran Jilid 2. Terjemah Drs. Benyamin Molan. PT Indeks Kelompok Gramedia.

Kotler, Philip Dan Armstrong, Gary. (2009). Prinsip-Prinsip Pemasaran, Edisi Kedua Belas Jilid I, Terjemah Bob Sabran MM, Jakarta: Erlangga.

Lupiyoadi, Rambat, (2013). Manajemen Pemasaran Jasa Berbasis kompentensi. Jakarta: Penerbit Salemba Empat.

Umar, Husein. (2008). Metode Riset Bisnis, Jakarta: PT. Gramedia Pustaka Utama.

Widitomo, Taufik. (2009). Analisis Pengaruh Kualitas Pelayanan dan FasilitasTerhadap Kepuasan Pasien Rawat Inap Keluarga Miskin (Studi pada RSUD kota Semarang).Skripsi Universitas Diponegoro, Semarang.

Widyawati, Fransisca. (2008). Pengaruh Persepsi Harga, Persepsi KualitasLayanan, dan Kualitas Produk Terhadap Kepuasan Pelanggan.Medan: Skripsi Fakultas Ekonomika dan Bisnis. 